\title{
Examining the Effectiveness of Simulated Interpreting Projects: Students' Perspectives
}

\author{
Wan $\mathrm{Hu}^{1}$ \\ ${ }^{1}$ School of Foreign Studies, Central University of Finance and Economics, Beijing, China \\ Correspondence: Wan Hu, 39 South College Road, Central University of Finance and Economics, Haidian District, \\ Beijing 100081, China. E-mail: huwan@cufe.edu.cn
}

Received: May 5, 2019 Accepted: May 31, 2019 Online Published: June 3, 2019

doi:10.5539/res.v11n2p118

URL: https://doi.org/10.5539/res.v11n2p118

\begin{abstract}
In recent decades, bridging the gap between university-based interpreting teaching and industry needs has been increasingly important as an emerging area of interpreter education and training. Many interpreter educators and practitioners have introduced authentic interpreting practices (e.g. mock conference, role-play, conference observation, field training) into their classrooms and received positive feedback from student interpreters. This study investigates the use of simulated interpreting projects, which have been designed by the interpreter trainer to make student interpreters' learning more stimulating and effective. Findings from this empirical study have demonstrated that the simulated interpreting projects not only enhanced student interpreters' skills for and knowledge about the interpreting profession, but also cultivated their vocational skills and investigation capabilities which are crucial for many other professions. This research contributes to the current understanding of enhancing student interpreters' learning experience via real-life activities. It introduces a fresh perspective for designing an investigative learning model for student interpreters. It also has practical implications for interpreting pedagogy, offering theoretical and empirical support for the changing attitudes and approaches in interpreter education and training.
\end{abstract}

Keywords: interpreter training; simulated interpreting project; innovative teaching approach; students' evaluations

\section{Introduction}

Translation and interpreting (T\&I) has become more important, frequent and necessary in the fields of international business, journalism, and science and technology. Many believe it is the most opportune time for educators to develop sound approaches to translator and interpreter training. In view of the approaches, T\&I scholars mainly focus on two dimensions: firstly, outcome-based training, aiming to develop students' translation and interpreting competences (Kelly, 2005; Göpferich, 2009; Kalina, 2000), and, secondly, content-based training, attempting to adopt different teaching methods (e.g. professional-based, learner-centred, process-oriented, task-based, project-based) in the T\&I classroom (Nord, 1991; D. Li, 2013; Inoue \& Candlin, 2015; Kiraly, 2005).

With regards to content-based interpreter training, the professional-focused approach has been one of the main topics, and students are always involved as "providers of natural data or subjects of experiments" (Takeda, 2010, p. 38). The professional-based ways of teaching aimed to provide real-life or authentic learning resources for student interpreters, which according to students, has been proven to be most effective. These real-life activities are mainly designed to cultivate students' skills or competences that professional interpreters require, or to familiarise students to the professional interpreters' working duties and responsibilities. The forms and content of these activities were controlled by the module convenors. However, fewer interpreting projects have been designed to explore students' adapting and research capabilities. These two aspects, are in fact crucial for university education and comprehensive professional development.

In order to fill the gap, this research introduced an investigative, student-centred interpreting model, conducted in a consecutive interpreting module for T\&I undergraduates. Within the model, students were required to investigate and accomplish a project by themselves, and to experience different roles involved in the interpreting-related profession. The teacher acted only as the consultant and commentator throughout the entire process, providing guidelines whilst evaluating students' performance. Lastly, the students' responses were then carefully considered to test the validity of this investigation-oriented learning model. 


\section{Changing Attitudes and Methods of Interpreter Training}

Due to a constantly changing market, as well as an increase in demand for high-quality interpreters, more comprehensive and efficient pedagogical methods are now required by educators and learners alike. In this sense, translator and interpreter training has shifted from skill-oriented training to authentic practice as well as the acquisition of professional norms (Wang, 2015). An increase in profession-oriented approaches such as mock conferences and dummy booth practice, along with international conference observations, are now being adopted in the interpreting classroom.

Mock conferences, or mock interpreting activities, have been a core curricular component in many leading T\&I postgraduate courses. This provides students with "highly simulated work environments and tasks", aiming to "enhance learners' capacity to think and act like professionals" (González-Davies \& Enríquez-Raído, 2016, p. 1). Student interpreters, in this scenario, can be exposed to real-life tasks and the career demands of a professional interpreter. Many T\&I scholars have stressed the necessity and importance of mock conferences in training high-calibre interpreters (De Laet, 2010; Weiss, 2012). Several of them, from a practical perspective, have embedded mock conferences in teaching advanced consecutive or simultaneous interpreting courses. For example, X. Li (2015, pp. 331-335) designed a systemic procedure of mock conferences. This new procedure was designed for Year 2 postgraduate T\&I students, in their conference interpreting module. Students' feedback proved the effectiveness of these conferences, which demonstrated an enhanced acquisition of interpreting-related skills. The students also perceived these as a satisfying learning experience. Similarly, in Hong Kong, Pan (2016) introduced simulated conferences in a T\&I programme that taught simultaneous interpreting. Research results generated after the conference showed that students regarded "authenticity", "confidence enhancement", "acquisition of procedure knowledge", and "peer learning" as the most beneficial areas of learning (pp. 119-121).

As previously mentioned, preparing students to face the demands of the interpreting profession can be achieved through the use of authentic teaching materials, as well as scenarios in a classroom setting (Kelly, 2005; Sandrelli \& De Manuel Jerez, 2007). Such preparation can also be achieved by removing learners from their familiar university 'learning space' (Kolb \& Kolb, 2005), while organising study visits for them to translation and interpreting agencies or international institutions. Chouc and Conde (2016) discussed the value and impact of placing postgraduate T\&I students to observe and to "practice mute-booth simultaneous interpreting" from a live Scottish parliamentary session in Edinburgh (p. 95). The replicated real-life interpreting assignments conducted, in this study, revealed that students had a better understanding of the interpreting profession. For example, students who participated in the live observation had a clearer awareness of the challenges in real-life interpreting tasks. This then provided them with "a more realistic perception of what constitutes suitable preparation for interpreting in a professional setting” (ibid., p. 102).

In line with the educational ethos of both cognitive apprentices (Collins, 2006) and situated learning (Lave \& Wenger, 1991), Chang \& Wu (2017) afforded T\&I graduate students with an opportunity to observe international conferences. This was conducted with professional interpreting services, where students were then asked to write reflective reports on the knowledge they gained. In order to enhance students' observation experience, the two researchers designed a conference observation form with detailed guidelines (p. 298). The document contained both comments on the interpreters' performance and students' own reflections on the correlation between the observing experience and their acquisition of interpreting competences. Regarding their observation experiences, all 17 participants responded positively. For example, they learned how to cope with demanding situations, such as fast-talking speakers. Observing professional interpreters' skills of effectively coping with mistakes also enlightened students' understanding. More importantly, student interpreters were made aware of the significance of lifelong learning (ibid., pp. 308-309). All in all, Chang \& Wu's empirical research did prove the effectiveness of observing professional interpreters in action. On the one hand, this demonstrated to students a professional interpreters' specific work environment and actual tasks. On the other hand, students were familiarised with the community of interpreting practice.

These previously mentioned teaching strategies all differed in geographical locations, class size, venues, and learner autonomies. However, they all investigated the possibilities of embedding professional requirements into a university-based interpreting programme. Moreover, these strategies replaced the traditional teacher-centred learning mode with more pioneering learner-centred experiences (Vienne, 1994; Kiraly, 2000; Kelly, 2005; Risku, 2005). These authentic strategies are mainly associated with two learning components: real-life international conference settings and a "controlled interpreting laboratory setting" (Chouc \& Conde, 2016, p. 93). 


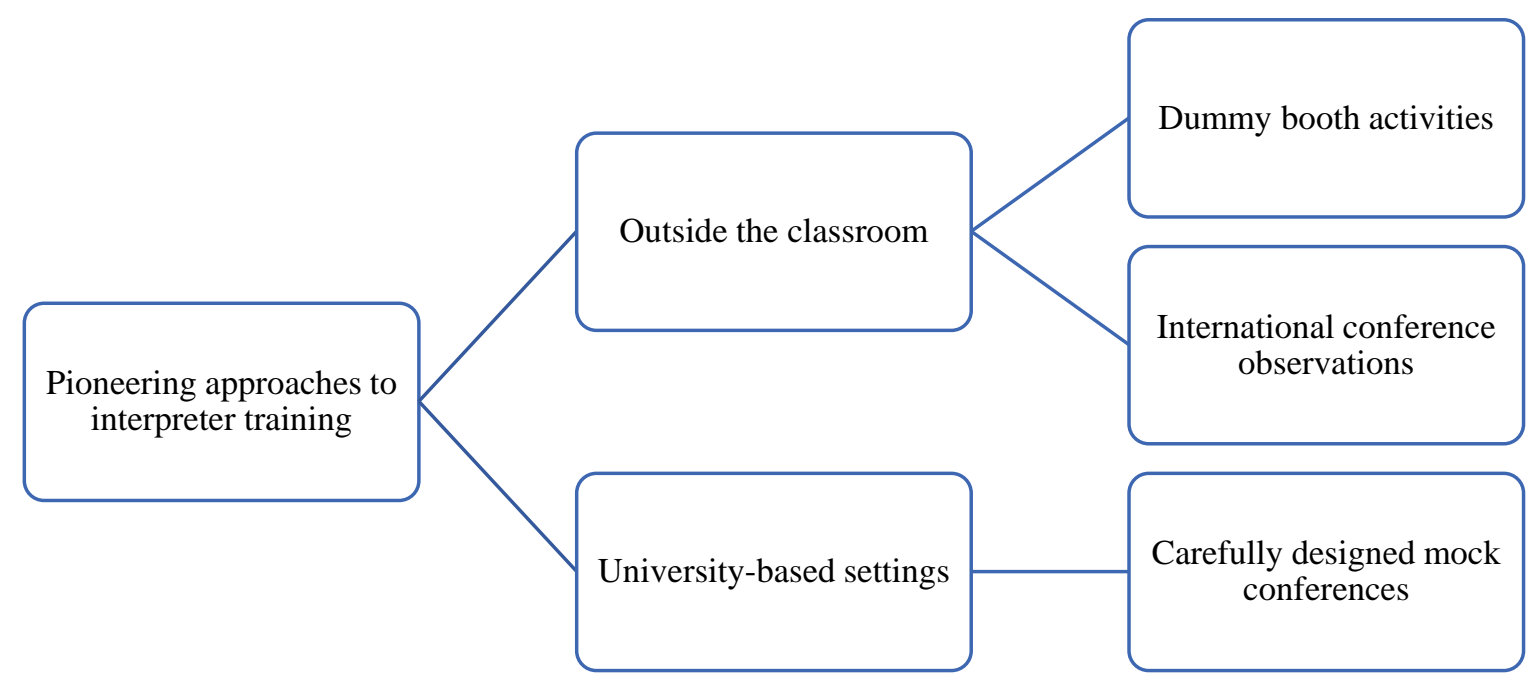

Figure 1. Pioneering approaches to interpreter training

The existing literature reviewed above focuses on the inherently skill-based nature of interpreting (Chouc \& Conde, 2016), paying more attention to the enhancement of student interpreters' professional awareness. The novel, innovative teaching strategies were more often adopted in teaching simultaneous interpreting, rather than consecutive or dialogue interpreting. Furthermore, most of the student participants were postgraduate level, already having acquired prior knowledge and skills of interpreting. However, there are fewer interpreting experiments at undergraduate level. Additionally, limited research has been conducted to develop student interpreters' abilities such as investigation, autonomously exploration, critical thinking, and group working skills. These abilities are in fact more welcome in teaching translation modules (Gonzaléz \& Díaz, 2015; L. Li, 2017), which are also highly desirable qualifications in the job market. Hence, this study attempts to introduce an explorative and research-oriented strategy in teaching interpreting at the undergraduate level, and aims to provide empirical examples to augment the current authentic approaches to interpreter training.

\section{The Research Model: The Approaches Taken for Data Collection and Analysis}

\subsection{Research Questions}

This research aims to provide answers to the following research questions:

Question 1: To what extent can student interpreters benefit from simulated interpreting projects?

Question 2: What are the limitations of the interpreting project, and in what ways can it be optimised?

Question 3: What are the implications for interpreting training in general?

\subsection{Research Method: Case Study}

Bearing in mind the research aims and questions, this study is dominated by one type of qualitative technique - the case study. A case study, as defined by Simons $(2009$, p. 21), is "an in-depth exploration from multiple perspectives of the complexity and uniqueness of a particular project, policy, institution, programme or system in a 'real-life' context". This emphasises the depth of analysis using a variety of data sources (Thomas, 2013; Baxter and Jack, 2008, p. 544), aiming to "provide insight into an issue or to revise a generalisation" (Stake, 2000, pp. 437-438). This research employs a consecutive interpreting module from a key university in China as a case study. It fully investigates the pedagogical effects of simulated interpreting projects, when teaching interpreting to undergraduates. To be more specific, the principal purpose is to provide further empirical evidence to the existing literature on the effectiveness of professional-focused teaching approaches. More importantly, by examining students' evaluations on the simulated interpreting projects, this study attempts to offer a fresh perspective on the correlation between university-based interpreting tasks and students' autonomous learning in this field.

\subsection{Research Implementation}

\subsubsection{Design of Interpreting Projects}

The simulated interpreting projects were conducted in the last four weeks of the Consecutive Interpreting module. This component has run every fall semester at the undergraduate level since 2016. This is a core module for Year 3 students, 
majoring in translation and interpreting, and the language combination is English and Chinese. Three year groups and 57 students enrolled in this module, and 40 out of 57 students (two year groups) participated in this study. Among these 40 student participants, 35 were female $(87.5 \%)$ and only 5 were male $(12.5 \%)$. These students were not only all in their early twenties, but also had similar educational backgrounds, and were at comparable learning stages when the interpreting projects were conducted.

The main principles and guidelines of designing the interpreting projects focussed on four perspectives. Firstly, the designed projects should be learner-centred. It was essential that "students themselves carried out the research and preparation, and not the teacher" (Seleskovitch \& Lederer, 1995, p. 68). Secondly, the designed projects should fit the scenarios of authentic dialogue interpreting work settings (X. Li, 2015), enabling students to have an "effective performance of real-life procedures" (González-Davies \& Enríquez-Raído, 2016, p. 9). Thirdly, selected topics should be of the right level of difficulty (Gilles, 2013). Last but not least, the interpreting projects could play a pivotal role in assessing whether students had achieved the intended learning outcomes of the learning module.

Students in each year group were divided into four sub-groups, and each sub-group designed one interpreting project under the supervision of the module convenor. The suggested projects were: 1) the Campus Recruiting Presentation of a multinational company. In this scenario, students took on different roles such as the speaker from the HR department, his/her interpreter, and audience members who would raise questions; 2) a lecture on International Climate Action given by a governmental department. This lecture was delivered to a delegation of Chinese officials. Students' roles were similar as for scenario 1;3) a business negotiation; the dialogue between company leaders after the merger and acquisition of two multinational companies. Negotiating contents included the respective roles and future directions. Students acted as senior company managers and their interpreters; 4) a dialogue between mayors of sister cities. Talks included the cooperative areas between the two cities and students acted as mayors and their interpreters, respectively. Each group could choose their own topic according to their interests.

In the preparatory stage, background documents including subjects, interpreting themes, presentation slides, and speakers' profiles were offered by the module convenor. However, students were still expected to prepare their own materials (e.g. background information, terminology, fixed expressions) for the given interpreting tasks with the help of the library and online resources. In addition, utilising the experience and skills of consulting professors, senior interpreters and industry experts was also actively encouraged. Considering authenticity and confidentiality, students who performed as speakers of each scenario, should not disclose their speech texts with student interpreters. During the preparatory stage, the module convenor acted as an "educational consultant" to answer questions from students.

On presentation days, students performed their tasks in a professional manner. The module convenor and an external examiner worked as commentators to construct critique. The comments mainly stemmed from three perspectives: accuracy of conveyed information, use of interpreting techniques, and professionalism.

\subsubsection{Student Reflection Reports}

In order to capture the authenticity and gain in-depth understanding of student perceptions on simulated interpreting projects, we used the student reflection reports for analysis. This report was formed with eight open-ended questions, which were then divided into three categories. The first classification dealt with students' learning experiences from the interpreting projects, including the enhancement of interpreting-related competences and the inspiration for future learning and practice. The second classification focused on the shift of students' understanding towards the interpreting profession, both before and after these interpreting projects. The final classification focused mainly on the challenges faced by students in the process of the simulated interpreting projects, and their suggestions for future improvement.

The student reflection reports were written in groups as the whole activities were conducted collaboratively. A minimum word count of each question was required, and set at 300 words. This was to negate the possibility of brief or incomplete feedback. As a result, eight valid reflection reports were collected, and each account contained at least 4000 words. To ensure anonymity, these eight accounts and student names were replaced with codes. In the following parts of the analysis, reflection reports were presented as GA, GB, GC, GD, GE, GF, GG, GH, whilst student names were noted down as S1, S2, S3, S4 .....S40. Since the focus of this research was on the efficacy of the interpreting project, the analysis of students' reports concentrated mainly on the students' perceived benefits and their recommendations for improvement. Such focused sets of data were analysed more relevantly and efficiently by these steps. 


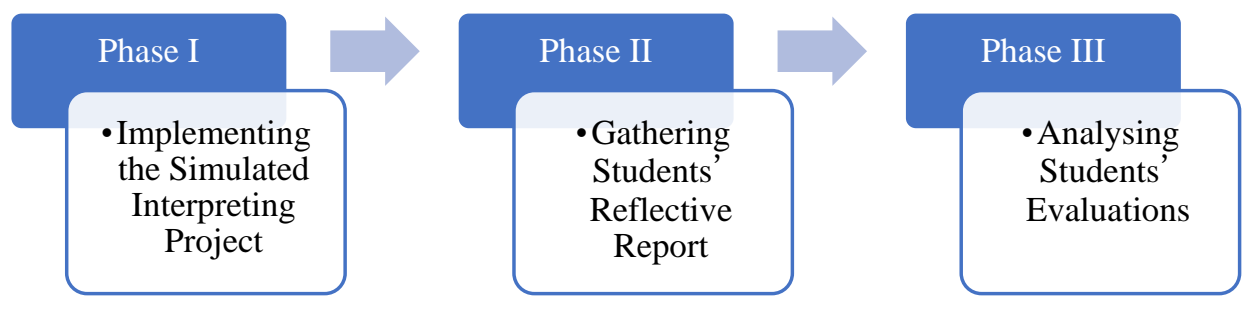

Figure 2. The Process of Data Collection and Analysis

\section{The Effectiveness of the Simulated Interpreting Projects: Students' Evaluations}

According to the student reflection reports, all the participants claimed that this simulated interpreting project provided them with an invaluable learning experience. It has assisted all with becoming familiar with real-life interpreting workflows, enhanced their disciplinary understanding of the interpreting profession, as well as consolidated their interpreting-specific competences. Furthermore, it has enhanced generic skills which are useful both in and outside the T\&I profession. The full list of students' perceived benefits from the simulated interpreting project is presented in Figure 3 below.

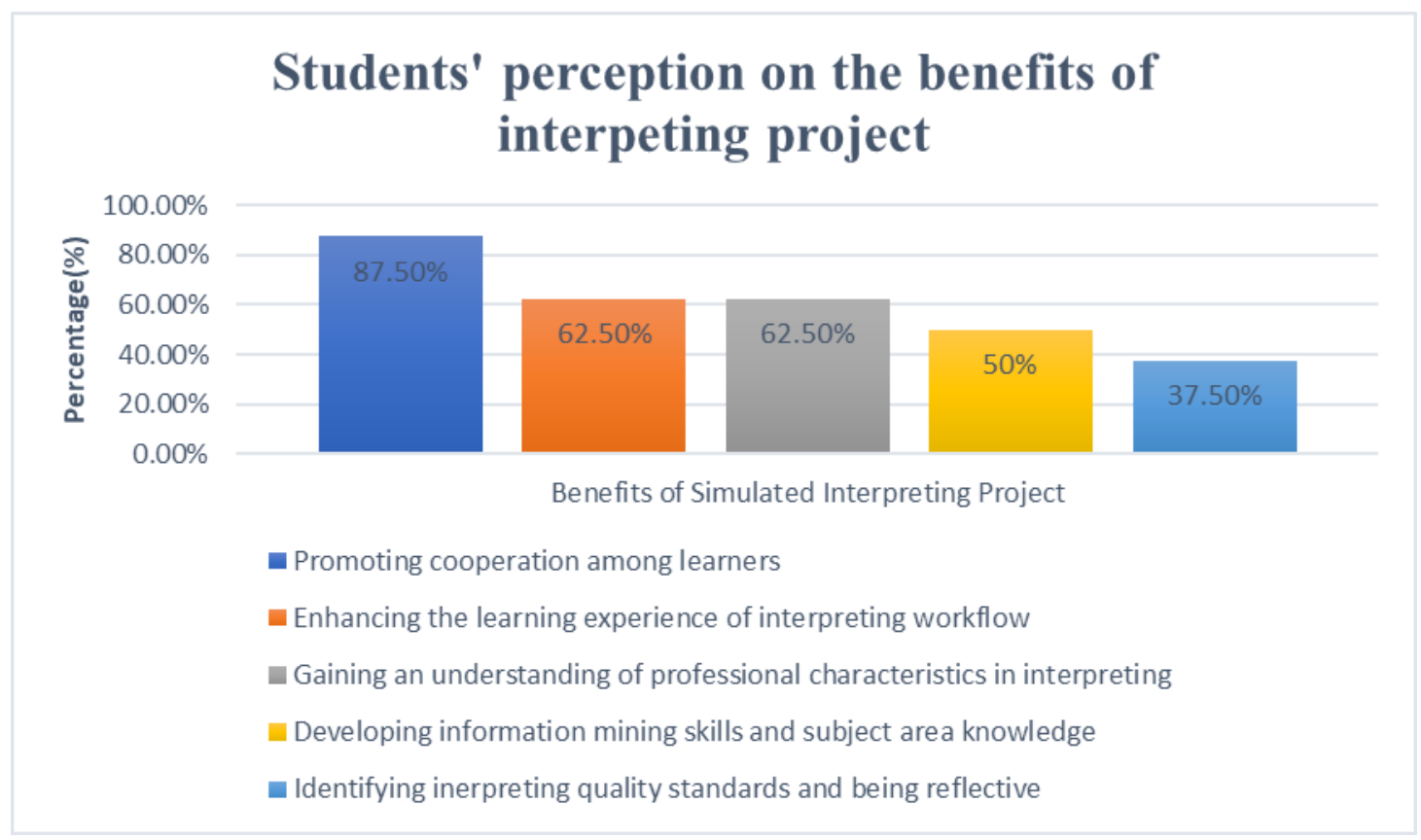

Figure 3. Students' perceptions on the benefits of the interpreting project

\subsection{Promoting Cooperation Among Learners}

Today, a translator is no longer sitting alone in front of his/her desk to accomplish tasks; instead, translation is becoming a group work. The situation is the same regarding interpreting activities. Interpreters may be required to work in a team with the speaker, other interpreters, or even event organisers to undertake a project in a professional context ( $\mathrm{Li}$, Zhang, \& $\mathrm{He}$, 2015, p. 15).

Teamwork is positive and worthwhile in translator and interpreter training for several reasons. One of the advantages is that it allows students to develop their own knowledge base through interactions with their classmates, teachers and experts in the field. Further, teamwork is able to improve students' interpersonal skills, which are in much demand by employers. It is therefore important for course designers and teachers, to be aware of the ability to work in a team. Introducing collaborative learning and collective responsibility will help student interpreters greatly, in the transition to the professional world.

In our project, working in groups became a very effective learning tool in both preparing and carrying out tasks for the interpreting project. The vast majority of the students (nearly $90 \%$ ) reported that this collaborative approach can create a dynamic and interactive environment for learning (Kiraly, 2006; AI-Shehari, 2017), which is enjoyable and stimulating at all stages of the interpreting projects. Despite the fact that students may be allocated to different roles (e.g. presenter, interpreter, interviewer, anchor project manager, etc.) in the group, they argued that they were equally engaged in the 
learning process via negotiating ideas, solving problems, and completing tasks together (Ames \& Murray, 1982; Dooly, 2008). Take the preparatory stage for example, after several discussions, students may report their 'consensus' or 'disparities' to the whole group and exchange ideas which will be beneficial to all parties because "they can work together to gather ideas and complete the task jointly". "The division of work among group members also increased work efficiency", added GC.

\subsection{Enhancing the Learning Experience of Interpreting Workflow}

Interpreting classes can adapt to the students by incorporating a host of pedagogical approaches and laying the emphasis on professional activities (Nunan, 1989, p. 40). One of the core principles is that these classroom activities are designed to help students discover and practise the skills which can be used to better meet the professional standards in the future. In other words, it is suggested that activities or tasks which imitate professional assignments (González Davis, 2004, p. 19), also called real-life activities, are included in the syllabus of translator and interpreter training.

More than half of the students claimed that this project offered them a precious opportunity to experience how interpreting work is actually carried out. This enabled them to link classroom-based interpreting exercises to a professional setting (Pan, 2016). Students claimed that they encountered the complete workflow of professional interpreters, working in different subject areas (e.g. business negotiations, political dialogues, and public lectures) via the interpreting projects. The interpreting projects largely complemented their learning on interpreting skills gained from previous weeks in the consecutive interpreting module.

The project served as a step-by-step guide for us to prepare for an interpreting task, to perform an interpreting assignment and to reflect on our interpreting quality. For example, group members who acted as interpreters had to research pertinent information, read previous meeting minutes, make up their own bilingual glossaries, confirm the programme or agenda, and anticipate the speaker. They realised that the most important thing for interpreting is preparation. For example, the interpreter needs to know what area of terminology and ad hoc knowledge he or she should prepare and how to prepare.

[GD]

As a student interpreter, I realised that it was not easy to apply the interpreting skills we learned in class, to a real interpreting job. We must have strong nerves and should be highly adaptive when taking on an interpreting project. This was quite different from the normal classroom settings. In class, we sat, took notes, and translated our materials in a friendly environment, whilst the interpreting project is more 'live'. We had to get accustomed to the speaker's accent, take into account the audience's response, deal with some unforeseen problems, and cope with tactics. All our performances were observed by the teacher, the commentator, as well as fellow students. In a nutshell, this project provided us with an opportunity to observe and role-play to learn the interpreting workflow. In this way, we formed a better understanding of the interpreters' roles and the interpreting profession.

$[\mathrm{S} 5, \mathrm{GE}]$

The topic for our group was the environment, climate change and new sources of energy. This topic included many institutions, NGOs, terminologies, and numbers. Although I prepared the glossaries and subject area knowledge of this address, there were still unpredictable moments where I had to cope with a difficulty. For example, in some parts of the speech, our speaker's delivery was too fast and too long, which put me under a great deal of pressure. I was too nervous to interrupt the speaker, and this affected my interpreting quality. After listening to the comments from my teacher, the interpreting expert, as well as my fellow students, I realised that I should check the delivery speed of the speaker before the interpreting assignment. Even during an assignment, I can still remind the speaker in a polite way.

$[\mathrm{S} 10, \mathrm{GF}]$

\subsection{Gaining an Understanding of Professional Characteristics in Interpreting}

Many students also believed that they were able to reflect on "what being professional is" upon the completion of these projects. Their gains mainly focused on two dimensions: 1) consolidated the professional skills required of a qualified interpreter; 2) better understood the concepts of professionalism, such as professional ethics, professional manners, communication skills, time management skills, and so forth.

With regard to professional skills, one of the potential benefits is to enable the students to consolidate their 
interpreting-specific skills, such as note-taking in professional settings, accurate rendition of the original utterance, and how to deal with practical difficulties that professional interpreters face:

The situation given for our group was an academic lecture delivered by a British professor to a delegation of senior officials from Chinese government institutions. The topic was about "international climate action". Both the situation and the topic were very formal. In this case, in addition to accurately translating the speaker's address, the register of the rendition should fit this situation. Formal discourse should be used, terminologies in this field should be carefully dealt with, while colloquial language should be omitted.

In our opinion, this interpreting project inspired us greatly for our future practical interpreting. For example, when as a professional interpreter, you suddenly cannot follow the speaker's information, how that problem is dealt with depends on the information's importance. If it is significant, you could ask the speaker at the end of a topic for additional information; if not, it would be better to omit the information, rather than blurring the speech. This project, in some sense, provided us with an opportunity to preview the situations that professional interpreters would encounter. Also, it gave us a precious opportunity to discover many hidden challenges in our daily study.

Many students also felt this experience taught them how to carry out an interpreting assignment professionally. For example, as students recognised, the interpreter should be punctual and should always behave professionally. This may include being sensitive and polite to organisers, speakers, and fellow interpreters, using an appropriate dress code, and having good public speaking skills (e.g. eye contact, conviction, and being heard clearly) during the interpreting assignment (GB, GC, GD, GE, GF, and GG). Professional code of conduct was another area where the students experienced obvious growth. As GC claimed, "preparing thoroughly is very important. Many government based terminologies we practised before were used in our setting: dialogue between mayors. Besides, through this experience, we realised that we should aim to work with professionalism and to strive for higher standards". Additionally, many students reported that effective communication and cooperation between interpreters, speakers, audiences, and T\&I industry experts were also important components of professionalism (GE, GC, GF, GG).

\subsection{Developing Information Mining Skills and Subject Area Knowledge}

As Gillies (2013) defines, interpreting is a combination of multiple skills, namely a person can explain and understand quite quickly, which requires learners to devote much of their time practicing both in and outside their classes. "Without consistent and deliberate practice, it is simply impossible to gain a skill or develop an expertise" (Bao, 2015). In some sense, however, the skill-oriented interpreting activity provides learners with relatively fewer opportunities for independent research and knowledge building.

There seems to be a consensus on the importance of preparation in real interpreting settings. Before starting the interpreting task, interpreters are expected to prepare and acquire as much ad hoc knowledge as possible (Gile, 2011, p. 134). The preparation can be done through conference documents, pre-conference briefings as well as library or online resources. This requires the interpreters to demonstrate strong "tool and research competence" (Göpferich, 2009, p. 65), and to develop their own knowledge base. In this sense, an important aim of the simulated interpreting projects is to enable students to know the "knowledge that they put together" (Hauke, 2018, p. 379), in order to "develop their own sense of expertise" (ibid., p. 379).

According to the student reflection reports, half of them stated that they had developed their information mining skills, and broadened the scopes of their subject-area competence during the projects. They also claimed that this was a precious opportunity for self-discovery and independent researching:

Although the teacher provided us with PowerPoint slides as reference material, it was still difficult for us to acquire all the content, including data, terminology, new vocabulary, charts, and images. We had to learn how to search topic-related information effectively, to choose appropriate resources, and to synthesise these different concepts and different sources to make them relevant to our own project. Apart from researching online, we consulted an expert to make the subject knowledge more explicit for us students. This process largely developed our documentary research ability. We also acquired capabilities regarding how to research relevant information for a given interpreting task. 
I think the most significant gains were how to investigate an unfamiliar subject area, and how to quickly become "an expert" in a specific area. The topic for our group was Mergers and Acquisitions $(\mathrm{M} \& \mathrm{~A})$. For our case, we chose the business negotiation after the $\mathrm{M} \& \mathrm{~A}$ activity, between Hilton Hotels and Hainan Airlines (HNA) in China. After comprehensive content preparation, I acquired the topic knowledge, such as the focus of a company after the M \& A, as well as some dynamic changes in strategic cooperation. I also had a holistic understanding of Hilton Hotels' and HNA's missions and visions, their business strategies as well as their operational status. Although the preparation time was brief, it is undeniable that this simulated interpreting project provided us with a good opportunity to get out of our comfort zones, and to consolidate our understanding of knowledge.

$[\mathrm{S} 1, \mathrm{GD}]$

\subsection{Identifying Interpreting Quality Standards and Being Reflective}

Some students also stated that they acknowledged practised quality standards of a professional interpreting task via listening to the motivational feedback from the teacher and industry expert:

After carefully listening to our teacher's insightful comments and through observing our fellow students' performances, we learned how to evaluate an interpreting act. In previous class sessions, we mainly focused on acquiring relevant interpreting skills, but this project offered us an opportunity by becoming aware of quality assessment criteria for interpreters, such as the conveying of accurate information, the appropriate use of skills, the professional issues, and so forth. These criteria are of great significance to our future practice and self-assessment.

Some other students also saw this interpreting project as an invaluable experience of self-reflection. From this perspective, they regarded interpreting not merely as a product, but more of a process. Once learners begin to reflect on their experiences, they may interpret what they acquire, and then construct their own knowledge (Kiraly, 2005, p. 1104).

It was the comments from the teacher, the industry expert and peer students that impressed us most. When working on the project, we hardly realised what we looked like, the standard of the interpreting quality, and whether the presentation was informative, interesting and professional. However, the comments and suggestions thereafter invoked us to rethink and reflect, and therefore truly acquired some insights.

When we were observing our fellow students' interpreting acts, we were able to examine the interpreters' live performance from the perspective of the external examiner. We may reflect on our own interpreting quality via their mistakes. This mutual-learning process was undoubtedly an interesting interactive process.

In addition to these frequently mentioned areas of growth, students found this project-based learning motivating. As GB clarified, "we can apply the knowledge and skills learned in previous weeks to this student-centred project, which was quite an innovative experience". Other groups of students echoed GB's opinions, saying "the project made the tasks more interesting, increased the involvement of the students, and bridged the gap between classroom teaching and practice" (GE, GF). Furthermore, several other students stated that they have enhanced their disciplinary knowledge of interpreting, and had better understandings of the interpreters' roles. Last but not least, students' feedback demonstrated that this project augmented their employability, and provided them with opportunities to consider for their future careers.

\subsection{Further Enhancement of the Simulated Interpreting Projects}

In spite of these obvious areas with growth, the researcher of this study also investigated students' learning challenges and their suggestions for future improvement. The results indicated that students preferred to have more explicit guidance on preparation as well as how to assure the quality of the group work, and include a session of peer assessment.

Firstly, in answering the survey question "if there were any parts of the interpreting projects you felt unable to participate fully, please list these below and briefly explain why you felt this way", the vast majority of the students $(87.5 \%)$ pointed out that they got stuck in preparing for the speech scripts. For instance, GI cited:

We thought the biggest difficulty was in the preparation. In terms of theme, we didn't know much 
about the topic of mayoral dialogue, and there was no similar video available on the Internet. This required us to design the agenda by ourselves under this theme. We also encountered difficulties in city selection. As the dialogue between mayors requires that the two cities share similarities or common issues, so because of these points, we were cautious in selecting cities. We also faced the problem of deciding the content of the dialogue at the mayoral level, in that there were too many fields available.

Another group of students expressed similar concerns, saying that:

Preparation was the most difficult session, especially with the choice of content. For example, global climate governance can be relevant with national and world-class institutions. What's more, some small and medium-sized organisations can also take part in it. So we had to decide the target of our project, to narrow the scope when researching for relevant material, and to hold discussions constantly. It was indeed very difficult for us to prepare for such a formal topic.

From students' feedback we can recognise that starting a brand new project from scratch can be very challenging for Year 3 undergraduates. This is partly because T\&I students, focusing more on language study, have less knowledge regarding politics, business, or climate change. It is therefore not easy for them to grasp a large amount of subject matter in a short period of time. Additionally, learners, especially Asian students, who are used to rote learning or teacher-centred learning may find it difficult to engage themselves in authentic or innovative learning environments (Kember, 2000). Therefore, when it comes to similar authentic learning tasks in the future, it is better to offer students an appropriate induction and much clearer instructions (D. Li, 2013, pp. 14-15).

Secondly, although group work was overwhelmingly welcomed by our students, this can also have some disadvantages. As an example, "not all the team members are glad to participate in the activities, and some members, especially self-confident students may have dominant attitudes. Furthermore, sometimes we found it difficult to trust the other team members, since some of them preferred to work individually and are not motivated to work as a cohesive team" (GA). In order to offer the most effective learning experience to students, a well-thought-out training in how to work in teams and ample coaching from their teachers can be embedded in the collaborative learning projects (Huertas Barros, 2011, p. 55).

Several groups of students suggested to introduce a session of peer assessment in future interpreting projects. They believed that "different people may pay attention to different points, therefore letting everyone speak freely and sharing their gains and reflections is much more helpful to both the interpreting group and everyone" (GI). Peer assessment, from a social constructivist perspective, has gained increasing attention in the higher education context (McGarr \& Clifford, 2013). This approach allows learners to value the quality of a product or performance of other learners with equal levels (Topping, 2009), and then to increase their engagement in learning. Peer assessment has been widely applied in the classroom of many disciplines in recent years. However, due to the lack of professionalism in interpreting and limited experience in marking, it is important for interpreting teachers to not only introduce students to carefully designed marking criteria but also to offer appropriate supervision or consultancy, if needed.

\section{Conclusion}

In the context of a core module for translation and interpreting, this research has demonstrated that an investigative, project-based method of training interpreters is welcomed by undergraduates. Their responses and evaluations validate the effectiveness of such an innovative and explorative training model.

Findings drawn from this empirical research highlight the usefulness of the simulated interpreting projects. The projects brought great benefits to students, by enhancing and re-enforcing interpreting professionalism, team work abilities, data mining and synthesising skills, as well as subject area knowledge. Project-based interpreting learning, from the perspective of meta-analysis, also enabled students to develop their independent learning capabilities and to acquire the skills needed for effective reflection. It can be concluded that the project can be acknowledged as a suitable strategy in teaching interpreting-related modules. This approach not only made students' learning more stimulating, but also promoted greater self-motivation for them. However, considering learner autonomy and students' prior knowledge, interpreting educators may need to provide students with carefully-designed structures (scaffolding) to rely on, when designing similar projects. With the help of the scaffolding, students may have the opportunity to reach a higher level of learning and find their knowledge more significant.

This research has multiple implications for interpreter training. It provides both theoretical grounds and further empirical evidence to the success of embedding real-life interpreting activities, in a classroom setting. This will, without 
doubt, enrich the field of innovative approaches to interpreter training. Pedagogically speaking, students' perceived advantages and disadvantages of the projects may be of use to interpreter trainers in other parts of the world. Interested educators in other regions could well be influenced by adopting or optimising this methodology in their teaching context.

The present research still has some limitations. It is constrained as it is small-scale in the terms of research participants. This research was undertaken in quite an unconventional teaching context, as English-Chinese interpreting practice, rather than other language combinations, was the focus in this study. It is therefore difficult to reach some generalisations, yet with further investigation, the study could be enlarged by the inclusion of more participants and language pairs. In addition to students' insights, perceptions from interpreter educators and industry insiders may also be taken into consideration.

\section{References}

AI-Shehari, K. (2017). Collaborative learning: trainee translators tasked to translate Wikipedia entries from English into Arabic. The Interpreter and Translator Trainer, 11(4), 357-372. https://doi.org/10.1080/1750399X.2017.1359755

Ames, G. J., \& Murray, F. B. (1982). When Two Wrongs Make a Right: Promoting Cognitive Change by Social Conflict. Developmental Psychology, 18(6), 894-897. https://doi.org/10.1037/0012-1649.18.6.894

Bao, C. (2015). Pedagogy. In H. Mikkelson, \& R. Jourdenais (Eds.), The Routledge Handbook of Interpreting (pp. 400-416). London and New York: Routledge.

Baxter, P., \& Jack, S. (2008). Qualitative Case Study Methodology: Study Design and Implementation for Novice Researchers. The Qualitative Report, 13(4), 544-559. https://nsuworks.nova.edu/tqr/vol13/iss4/2

Chang, C., \& Wu, M. M. (2017). From conference venue to classroom: the use of guided conference observation to enhance interpreter training. The Interpreter and Translator Trainer, 11(4), 294-315. https://doi.org/10.1080/1750399X.2017.1359759

Chouc, F., \& Conde, J. M. (2016). Enhancing the learning experience of interpreting students outside the classroom. A study of the benefits of situated learning at the Scottish Parliament. The Interpreter and Translator Trainer, 10(1), 92-106. https://dx.doi.org/10.1080/1750399X.2016.1154345

Collins, A. (2006). Cognitive Apprenticeship. In R. K. Sawyer (Ed.), The Cambridge Handbook of the Learning Sciences (pp. 47-60). Cambridge: Cambridge University Press. https://doi.org/10.1017/CBO9780511816833.005

De Laet, F. (2010). Mock Conference: A Challenge for Trainer and Trainee. In V. Pellatt, K. Griffiths, \& S. Wu (Eds.), Teaching and Testing Interpreting and Translating (pp. 251-260). Berlin: Peter Lang.

Dooly, M. (2008). Constructing Knowledge Together. In M. Dooly (Ed.), Telecollaborative Language Learning. A Guidebook to Moderating Intercultural Collaboration Online (pp. 21-45). Berlin: Peter Lang.

Gile, D. (2011). Basic Concepts and Models for Interpreter and Translator Training (revised ed.). Shanghai: Shanghai Foreign Language Education Press.

Gillies, A. (2013). Conference Interpreting: A Student's Practice Book. London \& New York: Routledge. https://doi.org/10.4324/9780203114926

González, D. M. (2004). Multiple Voices in the Translation Classroom. Amsterdam/Philadelphia: John Benjamins. https://doi.org/10.1075/btl.54

González, D. M., \& Enríquez-Raído, V. (2016). Situated learning in translator and interpreter training: bridging research and good practice. The Interpreter and Translator Trainer, 10(1), 1-11. https://doi.org/10.1080/1750399X.2016.1154339

González, M. G., \& Díaz, M. T. V. (2015). Guided Inquiry and Project-Based Learning in the field of specialised translation: a description of two learning experiences. Perspectives: studies in translatology, 23(1), 107-123. https://doi.org/10.1080/0907676X.2014.948018

Göpferich, S. (2013). Translation competence: Explaining development and stagnation from a dynamic systems perspective. Target, 25(1), 61-76. https://doi.org/10.1075/target.25.1.06goe

Hauke, E. (2019). Understanding the world today: the roles of knowledge and knowing in higher education. Teaching in Higher Education, 24(3), 378-393. https://doi.org/10.1080/13562517.2018.1544122

Huertas, B. E. (2011). Collaborative learning in the translation classroom: preliminary survey results. The Journal of Specialised Translation, 16, 42-60.

Inoue, I., \& Candlin, C. (2015). Applying Task-Based Learning to Translator Education: Assisting the Development of 
Novice Translators' Problem-Solving Expertise. Translation and Interpreting Studies, 10(1), 58-86.

Kalina, S. (2000). Interpreting Competences as a Basis and a Goal for Teaching. The Interpreters'Newsletter, 10 , 3-22.

Kelly, D. (2005). A Handbook for Translator Trainers. Manchester: St. Jerome Publishing.

Kember, D. (2000). Misconceptions about the Learning Approaches, Motivation and Study Practices of Asian Students. Higher Education, 40(1), 99-121. https://doi.org/10.1023/A:1004036826490

Kiraly, D. (2000). A Social Constructivist Approach to Translator Education. Empowerment From Theory to Practice. Manchester: St. Jerome Publishing.

Kiraly, D. (2005). Project-Based Learning: A Case for Situated Translation. Meta: Translators' Journal, 50(4), 1098-1111. https://doi.org/10.7202/012063ar

Kiraly, D. (2006). Beyond Social Constructivism: Complexity Theory and Translator Education. Translation and Interpreting Studies, 1(1), 68-86. https://doi.org/10.1075/tis.1.1.05kir

Kolb, A. Y., \& Kolb, D. A. (2005). Learning Styles and Learning Spaces: Enhancing Experimental Learning in Higher Education. Academy of Management Learning \& Education, 4(2), $193-212$. https://doi.org/10.5465/amle.2005.17268566

Lave, J., \& Wenger, E. (1991). Situated Learning. Cambridge: Cambridge University Press. https://doi.org/10.1017/CBO9780511815355

Li, D. (2013). Teaching Business Translation: A Task-based Approach. The Interpreter and Translator Trainer, 7(1), 1-26. https://www.tandfonline.com/doi/abs/10.1080/13556509.2013.10798841

Li, D., Zhang, C., \& He, Y. (2015). Project-based learning in teaching translation: students' perceptions. The Interpreter and Translator Trainer, 9(1), 1-19. https://doi.org/10.1080/1750399X.2015.1010357

Li, L. (2017). Training undergraduate translators: a consciousness-raising approach. The Interpreter and Translator Trainer, 11(4), 245-258. https://doi.org/10.1080/1750399X.2017.1359757

Li, X. (2015). Mock conference as a situated learning activity in interpreter training: a case study of its design and effect as perceived by trainee interpreters. The Interpreter and Translator Trainer, 9(3), 323-341. http://dx.doi.org/10.1080/1750399X.2015.1100399

McGarr, O., \& Clifford, A. (2013). Just enough to make you take it seriously: exploring students' attitudes towards peer assessment. Higher Education, 65(6), 677-693. https://doi.org/10.1007/s10734-012-9570-z

Nord, C. (1991). Text Analysis in Translation: Theory, Methodology, and Didactic Application of a Model for Translation-Oriented Text Analysis. Amsterdam: Rodopi.

Nunan, D. (1989). Designing Tasks for the Communicative Classroom. Cambridge: Cambridge University Press.

Pan, J. (2016). Linking classroom exercises to real-life practice: a case of situated simultaneous interpreting learning. The Interpreter and Translator Trainer, 10(1), 107-132. http://dx.doi.org/10.1080/1750399X.2016.1154346

Risku, H. (2002). Situatedness in Translation Studies. Cognitive Systems Research, 3(3), 523-533. https://doi.org/10.1016/S1389-0417(02)00055-4

Sandrelli, A., \& De Manuel Jerez, J. (2007). The Impact of Information and Communication Technology on Interpreter Training: State-of-the art and Future Prospects. The Interpreter and Translator Trainer, 1(2), $269-303$. https://doi.org/10.1080/1750399X.2007.10798761

Seleskovitch, D., \& Lederer, M. (1995). A Systematic Approach to Teaching Interpretation (English translation) by J. Harmer of Seleskovitch, D. and Lederer, M. (1989), Pedagogieraisonnée de l'interprétation, 1st ed., The Registry of Interpreters for the Deaf.

Simons, H. (2009). Case Study Research in Practice. London: Sage. https://doi.org/10.4135/9781446268322

Stake, P. (2000). Case studies. In N. Denzin \& Y. Lincoln. (Eds.), Handbook of Qualitative Research (pp. 435-454). Thousand Oaks, CA: Sage.

Takeda, K. (2010). What interpreting teachers can learn from students: A case study. The International Journal for Translation \& Interpreting Research, 2(1), 38-47.

Thomas, G. (2013). From question to inquiry: operationalising the case study for research in teaching. Journal of Education for Teaching, 39(5), 590-601. http://dx.doi.org/10.1080/02607476.2013.852299

Topping, K. (2009). Peer Assessment. Theory into Practice, 48(1), 20-27. https://doi.org/10.1080/00405840802577569 
Vienne, J. (1994). Toward a Pedagogy of 'Translation in Situation'. Perspectives: studies in translatology, 2(1), 51-59. https://doi.org/10.1080/0907676X.1994.9961222

Wang, B. (2015). Bridging the Gap Between Interpreting Classrooms and Real-World Interpreting. International Journal of Interpreter Education, 7(1), 65-73.

Weiss, K. A. (2012). Customization in Designing a Course for Interpreter Training. Journal of Modern Languages and International Studies, 1(1), 7-20.

\section{Copyrights}

Copyright for this article is retained by the author(s), with first publication rights granted to the journal.

This is an open-access article distributed under the terms and conditions of the Creative Commons Attribution license (http://creativecommons.org/licenses/by/4.0/). 